\title{
Mutton Cut Up As Lamb Mothers, Daughters and Cosmetic Surgery
}

We are surrounded by the image of the woman's face, the obsession of the portrait and the cover girl alike. The face is what belongs to the other; it is unavailable to the woman herself. (Susan Stewart, On Longing, 1993:125)

\begin{abstract}
Cosmetic surgery is a fast-growing industry in Australia and has become a perennial subject of articles in popular women's magazines. In addition to this, a number of glossy magazines specialising in cosmetic surgery have recently appeared. This paper identifies a sub-genre common to both types of magazine: the article, editorial, or comment that focuses on mothers, daughters, and cosmetic surgery. Such pieces usually feature celebrity mother/daughter comparisons but may also include the narratives of 'normal' people. Two examples of the sub-genre, from the magazines $N W$ and Gloss, are analysed. It is argued that they strongly express a contradiction that lies at the heart of discourses around contemporary cosmetic surgery, namely, that while cosmetic surgery works to annihilate the markers of ageing, it simultaneously relies on a continued divide between age and youth. Cosmetic surgery is identified as a medical/beauty technology that works in largely constricting ways: it promises empowerment but in fact locks mother and daughter together in a destructive Oedipal symbiosis. Finally the article offers two alternative deployments and readings of cosmetic surgery: one that embraces grotesque corporealities and blurs lines between radical body modification practices and cosmetic surgery; and one that suggests that while generational tensions are highlighted by mainstream cosmetic surgery discourse, the practice may offer opportunities for new connections between mother and daughter.
\end{abstract}

\section{Introduction}

Cosmetic surgery is not merely a medical discipline, nor a set of surgical techniques exercised on human bodies. Rather, it is a series of interlocking practices and discourses comprising medical and surgical techniques as well as many media forms such as academic analyses, advertisements, autobiographies, feminist writing, histories, medical literature, popular magazines, and regulatory/legal texts. (Davis, (1995, 1998, 2002, 2003a, 2003b; Haiken, 1997; Gilman, 1999; Blum, 2003; Fraser, 2003) My wider project - a PhD dissertation that situates cosmetic surgery as part of what I call our 'Makeover Culture' ${ }^{1}$ - examines the multifarious disciplines, endeavours, industries, cultural logics, and normative values that shape the ongoing construction of contemporary cosmetic surgery. It is impossible to attempt a cultural analysis of cosmetic surgery without paying close attention to the media and cultural products that comment upon and also produce it. It is these products that express the deployment of cosmetic surgery as desirable/undesirable or normal/abnormal; its results as beautiful/ugly; and its experience as excruciating or just mildly 
uncomfortable. A close-reading approach to a particular set of texts and images works, prism-like, to direct light on some of the broad cultural logics that surround cosmetic surgery. In her excellent book Cosmetic Surgery, Gender and Culture (2003) Suzanne Fraser reflects on how gender and femininity are intrinsically bound up in the various discourses around cosmetic surgery: she helpfully identifies a number of cosmetic surgery genres, including the popular magazine genre (2003: 6196). Building on Fraser's scholarly findings I locate a sub-genre inside the magazine genre - the mother/daughter/cosmetic surgery story - and explore it here.

\section{Youth, Old Age, and the Stretched Middle Age}

You love your mum. Sure you do. But be honest. Have you ever noticed the Serious Crow's Feet Problem she has? Winced at the way her chin triples itself? Ever thought quietly to yourself, heck, I hope I don't take after her in all departments? (Gloss: The Essential Anti-Ageing Magazine, 1998:26)

The quote above is from a now-defunct Australian publication called Gloss: The Essential Anti-Ageing Magazine. Although this particular magazine didn't have a long life, it is part of a group of high-production 'glossies' that emerged in the late 1990s in Australia, including Australian Cosmetic Surgery Magazine, The Art of Cosmetic Beauty, and Body, Health and Beauty, which are still in circulation. They are merchandised in newsagents' women's magazine sections and claim they are devoted to providing information and useful advice about beauty products, cosmetic surgery, health, ageing, and well-being. ${ }^{2}$ They are at the expensive end of the magazine market at $\$ 10.95$.

In an era where the health of aged individuals is better than it has ever been because of improved cancer treatments, effective medications for heart disease, and an increasing availability of prosthetic devices such as artificial hips, we might suppose that the prospect of old age - at least in the wealthy first world - would be more palatable than ever. But media and popular culture representations of old age, as evident in the quote above, overburden the public consciousness with negative stereotypes, which result in a dread of impending old age. While youth is granted privileged status and is associated with active sexuality, independence, beauty, and productivity, ageing is often represented as its opposite: frail, useless, unattractive, and dependent. (Friedan, 1994; Bytheway, 1995; Biggs, S. 1999; Gilleard and Higgs, 2000; Macdonald, 2001) ${ }^{3}$ The rise of the "cult of youth' ${ }^{4}$ has been proportional to the decline of old age as a respectable, productive and interesting state of life. (Fischer, 1978; Gillis, 1975, 1993) Mike Featherstone and Andrew Wernick put it succinctly: '...consumer culture with its images of youth, fitness and beauty lifestyles... produced a new set of exclusions of older people.' (1995: 7) Negative representations and views of the elderly almost certainly lead to social, political, legal, and medical discrimination (Biggs, H. 2002: 175). For women, ageing also means being squeezed into either invisibility or being represented as generally unattractive: '...for western women, aging has been and may yet be experienced as a kind of 'trauma.' (Kaplan, 1999:171; also De Beauvoir, 1970; Woodward, 1995; Gullette, 1997, 2004) Kathleen Woodward points out that youth culture currently works hand in hand with patriarchy in the denigration of older women: she quotes activist lesbian Barbara MacDonald: 'youth is bonded with patriarchy in the enslavement of the older woman. There 
would, in fact, be no youth culture without the powerless older woman' (1995:89). Similarly, there would be no such thing as 'youthful beauty' without its opposite, aged ugliness. The cartoon shown here (figure one) expresses this incongruity very well (turn it upside down), showing the perceived intertwining of mother and daughter, the way that women's beauty is only really ever presented as the flip side to ugliness (Tseëlon, 1995), and the way that representations of beauty are nearly always associated with youth.

Figure 1 - This cartoon has been in circulation for many years. Available at www.awardsite.org/ pwp/beer.htm ${ }^{5}$

In this paradigm, active resistance to ageing is an important consideration for many adults and can even constitute a 'lifestyle.' Chris Gilleard and Paul Higgs argue that the quest for good health and the prevention of morbidity are now 'central to the renegotiation of public and private responsibilities in contemporary society.'

(2000:128) Care of the body is increasingly interwoven with social responsibility, as 'costly old age' is seen to drain the health and welfare systems. Body disciplines that minimise use of medical resources and help contribute to a person remaining 'productive' into old age come to be seen as virtues. (Chaney, 1995; Gilleard and Higgs, 2000:128) The postmodern virtuous old age - especially for women - is one that abandons traditional notions of age as a time of stasis and rest, obligating its subjects to perform 'lifestyles' until the day they die. (Katz, 1995:69) One editorial says, 'In the future, there will be no excuse for looking a day over the age of 35.' (Boland: 1998:28) Middle age then, is not a transit lounge passively inhabited between youth and old age. It is an increasingly significant, actively worked-upon life-phase. I call it the 'stretched middle age.'

In the schema of the stretched middle age a person's corporeal chronology is rendered less significant than their perceived ability to elasticise their middle age by way of pharmaceuticals, hormone replacement therapies, body modifications such as dieting and exercise, social activities, financial independence, and the compulsory 'youthful outlook.' Cosmetic surgery is an increasingly important element in the toolkit for the stretched middle age, and in this paradigm, contrary to appearances, it is less about reclaiming or reinventing youthfulness, and more about attempting to create a look of indeterminate age or 'agelessness.'

In allowing people to control the aesthetics of their ageing process, it can be argued that anti-ageing cosmetic surgery is not about denying ageing but rather about designing it. Another way to articulate this is through a phrase I've adopted from some of the people I've interviewed ${ }^{6}$, which is that the aim of cosmetic surgery is to make people to look 'better, not younger.' This positive rhetoric is common across many cosmetic surgery discourses, from medical textbooks, to guides to finding a surgeon, to Internet advertising. It works to move the perception of cosmetic surgery from being a desperate attempt to recapture youth towards being about part of an interesting enactment of a new kind of existential temporality, something that I examine in my larger project. However, within this overarching semi-utopic view on cosmetic surgery that I suggest, there are some difficult and contradictory discursive actualities: one of them is specifically expressed in the sub-genre that is the mother/daughter/cosmetic surgery article, some examples of which are analysed below. 


\section{Mothers' and Daughters' Age Old Problem}

I focus here on one piece from $N W^{7}$ and one from Gloss: they are both multiple-page spreads specifically devoted to the issue of mothers, daughters, and cosmetic surgery. ${ }^{8}$ Predictably, they position cosmetic surgery as an antidote to the aesthetic effects of ageing: less predictably, they advocate cosmetic surgery as a 'solution' for youthful daughters as well as for ageing mothers. Gloss has a suite of interviews, articles, and commentaries collected under the headline 'Like Mother, Like Daughter.' The $N W$ piece is called 'Age old problem.' (2002:22-25) It places stars' ages next to their names and gives them an ageing score out of ten on the 'wrinkle rater.' Interestingly, the score is not based on the star's looks but on her mothers' (figure two).

Figure 2 - Jennifer Lopez and her mother, $N W$, Australian Consolidated Press, Australia, January 21 2002:23. Copyright Getty Images Entertainment

Each star in this article is paired with her mother, and it is the mothers' faces that come under vicious scrutiny: they are criticised for having sagging jowls, laughter lines, turkey-gobbler necks, permanent frowns, tired eyes, crows feet, and thick noses. These features are presented as ominous signs of what lies ahead for the still-beautiful daughters. We're told that in twenty years' time, Gwyneth Paltrow will be 'wrestling with wrinkles,' Geri Halliwell will have 'thin lips,' Catherine Zeta-Jones will have 'heavy eyelids,' while poor Nicole Kidman 'is already showing the problem areas that will plague her in old age.' Of the nine celebrity daughters compared to their mothers here, only one is determined by the expert cosmetic surgeon - who was 'consulted' by the journalist, obviously, not by the celebrities - as being unlikely to eventually require cosmetic surgery.

The aim of this kind of scrutiny and almost apocalyptic rhetoric is to keep the ageing female body within the borders of acceptable femininity - that is, youthful femininity - by predicting and 'fixing' transgressions even before they occur. The ideal feminine body must be presented as youthful, or at least as trying to appear youthful. (De Beauvoir, 1970; Fraser, 2003; Gullette, 2004) As Simone De Beauvoir painfully notes:

From the day a woman consents to growing old, her situation changes. Up to that time she was still a young woman, intent on struggling against a misfortune that was mysteriously disfiguring and disforming her; now she becomes a different being, unsexed but complete: an old woman. (1970:595, my italics)

So legitimate and acceptable femininity has two forms: one genuinely youthful, the other dedicated to simulating a youthful appearance. Thus, cosmetic surgery is easily presented as something that's utterly correct to desire and indeed crucial in the enactment of ageing: it is presented as an indispensable rather than an optional tool for the stretched middle age. 
Figure 3 - Blythe Danner and Gwyneth Paltrow, Gloss: The Essential Anti-Ageing

Magazine, Atlantic and Pacific Publishing, Sydney, October/November 1998: $24^{9}$

While the article in $N W$ works by emphasising perceived negatives due to ageing in the faces of the mothers, a similar piece in Gloss works by complimenting the mothers for the cosmetic surgery they are deemed to have had. Three sets of mother/daughter celebrities are analysed in this piece, which is written by one of Sydney's most famous cosmetic surgeons, Darryl Hodgkinson, who has a very high media profile himself. He estimates, from photos, that all three of the mothers have had extensive cosmetic surgery, ranging from three to seven operations each (figure three). He describes the mothers in glowing terms: Blythe Danner, Gwyneth Paltrow's mother, is 'quite youthful,' Ivana Trump, mother of Ivanka, is 'transformed,' and Janet Leigh, mother of Jamie-Lee Curtis, is 'very pretty.' The daughters' faces are analysed against the mothers' to see how they will fare in comparison, and Hodgkinson categorically states: '[f]or all of these stars to maintain a youthful appearance, cosmetic surgery will be required as each generation ages.' $(1998: 24)$

Intriguingly, both of the articles feature the Hollywood actress Gwyneth Paltrow and her mother Blythe Danner. Two very similar photos of the pair are used to illustrate seemingly contradictory arguments: while the $N W$ article states that Danner's 'jowls' are a big problem, the Gloss article suggests she has probably had a nose job, facelift, browlift, and eye surgery, and compliments her on her 'youthful appearance.' $N W$ analyses the mother's face unfavourably and presents her as having not had cosmetic surgery: the daughter is duly warned about how not to take after her. Gloss examines the mother's face positively, assuming she has had cosmetic surgery, and she is complimented on having corrected her faults: here, the daughter is told she should follow in her mother's footsteps or risk ugliness. So although the articles treat the mother quite differently - in one she is praised while in the other she is ridiculed - the shared conclusion is that the daughters will definitely need cosmetic surgery.

These articles lock mother and daughter together in endless mirrored pairings, where each can only refer to the other. ${ }^{10}$ The mother is forced to look at the youthful beauty that she no longer has, while the daughter sees the utterly undesirable face of what she will inevitably become. The mother/daughter relationship is represented as symbiotic: pictures from both articles show mother and daughter as intertwined, overlapping, and touching. Each couple is carefully framed so they're on their own: mother and daughter have no reference points apart from each other. Different colours separate the different pairs and some images even have their backgrounds removed, so the visual language here implies that this twinning is all there is: mother and daughter are inseparable. The mother's wrinkles are presented as active and malevolent, about to invade the daughter and take her over, while the daughter's youthful beauty haunts the ageing mother, constantly reminding her of her own shrinking lack.

\section{Jocastan Power}


The turning-away from her mother is an extremely important step in the course of a little girl's development. (Sigmund Freud, quoted in Hirsch, 1989:91)

There's something a bit weird about a mother and daughter who look the same age. Both Priscilla and Lisa Marie Presley are said to be fans of plastic surgery and, as time passes, whatever work they're having done seems to be turning them into twins. (Anonymous, 2002:22-23)

... mothers and daughters need alternative models for relating to one another outside the 'family plot'... (Ruth E. Ray, 2003:113)

Figure four shows Lisa Marie, Elvis Presley's daughter (below) with her mother Priscilla (above). These two women have done precisely what the $N W$ and Gloss articles seem to recommend: they have taken full advantage of aesthetic technologies of the self, particularly cosmetic surgery, and each is carefully performing the stretched middle age. They are ridiculed for their efforts whilst simultaneously being held up as beautiful individuals to be emulated. The incongruous rhetoric shows how the enactment of the stretched middle age has the potential to render Oedipal anxieties impotent, by positioning mother and daughter more as 'equals,' but that it also gives rise to huge fears and desires about the loss of clear generational differences. Fear and desire are the emotions at the nexus of cosmetic surgery, particularly anti-ageing cosmetic surgery, and contemporary popular texts like those analysed here emphasise both the yearning for a closure of the generation gap and a horror of losing traditional markers of, and margins between, age groups.

Figure 4 - Priscilla Presley ${ }^{11}$ and Lisa Marie Presley, $N W$, Australian Consolidated Press, Australia, September 30 2002:23. Copyright for photo of Lisa Marie Presley Getty Images Entertainment

This juxtaposition of fear and desire shown here highlights an inconsistency that lies at the heart of all discourse around anti-ageing cosmetic surgery, which is that while it deconstructs or even annihilates the markers of ageing, it is nevertheless utterly reliant on a continued divide between age and youth. Hence, in order to promote anti-ageing cosmetic surgery as a tool with which to enact middle age 'properly,' many texts around it reinforce repressive generational stereotypes whilst simultaneously promising escape from them. By privileging the fraught paradigm of the two-handed mother/daughter struggle women are locked into the unbeatable slow machine of clocked and chronological time. The grimmest extension of this viewpoint is that we view the future with a sense of dread and loss, looking either at our daughters, who flaunt the youth that we have lost, or at our mothers, who inhabit the undistinguished, unrespected position that awaits us as we inevitably age and decline (see note viii). It is this sad paradigm that texts such as the $N W$ and Gloss articles analysed above present: in the guise of offering transformation and escape from destinies that are always presented as undesirable they shut down the possibilities of alternative temporalities and in fact lock us into a constant battle against time. 
The stretched middle age means that old and clear boundaries between generations are blurred. As technologies of the self - from hair dye to cosmetic surgery to bioreproductive developments - increase they bring anxieties and even panics to the surface. These mother/daughter/cosmetic surgery texts express that alarm beautifully because they recognise the possibilities of technologies that render age less definable and promote the body as more malleable, therefore offering all sorts of potential new freedoms and novel experiences of temporality and spatiality. But they are also tragically caught up in a deep-rooted mythic horror of compounded generations: the classic Oedipal state where two adjacent generations struggle and even war with each other.

Freud's Oedipal complex - wherein the young boy wishes to become his father, naïvely at first by desiring to marry his mother and kill his father - is part of the boy's development as a human, moving him from the presocial to the social and allowing him to achieve maturation as an individual both within the family and the wider society. (Gatens, 1996:52-53; Hirsch, 1989:28-29) In relation to women, the Oedipal complex can be used to describe conditions where women compete with, undermine, or hurt each other in order to be more successful within a patriarchal system. Hence ' $[\mathrm{t}] \mathrm{he}$ bond between mother and daughter, daughter and mother, must be broken so that the daughter can become woman.' (Iragaray, Ethique, 1984:106, translated by and quoted in Hirsch, 1989:43)

Going back to the Ancient Greek drama that Freud used as his template for the complex we see that while Oedipus commits material crimes of incest and patricide, these flag a far greater offence to do with his correct position in time: he oscillates between generations, ignorant of his proper place, travelling 'backwards' to marry his mother and 'forwards' to become his daughters' brother. Keeping this in mind and turning the prism slightly to focus on the mother he marries, Jocasta, we can theorise a 'Jocastan Complex' where the mother becomes or remains powerful and desirable by challenging her assigned place in chronological time. She marries her son, becoming 'younger,' and experiences dual or triple relationship roles (as mother/grandmother/sister) with her daughters. She is the pivot in a series of events that twist the normal flow of time: she refuses the negative role assigned to her because of her age. Partaking of cosmetic surgery might then described as a Jocastan action: it is one way for women to hang onto or regain central positions in the active adult world, avoiding the marginalisation that comes with age.

In Oedipal situations tensions and confusions - and of course tragedies - occur because of generational enmities. Oedipal nightmares result from families being too intimate (in Sophocles' Oedipus of course it is actual reproductive incest), so the urge to flee such closeness is strong. One way of viewing anti-ageing cosmetic surgery and the stretched middle age positively is as a way to alleviate Oedipal tensions, by simply allowing mother and daughter to occupy the same temporal space, and to effectively banish the generation gap, at least aesthetically. While the daughter may use cosmetic surgery to escape the tyranny of her mother's genes and to distance herself from her aesthetic fate, the mother concurrently uses cosmetic surgery to come closer to how the daughter looks. But this coming together is highly problematic, because cosmetic surgery, while seeming to offer an alternative to Oedipal tensions by minimising the generation gap, also does exactly the opposite: we can see from this analysis of one particular sub-genre that in fact cosmetic surgery relies on 
perpetuating mythic fears - that are grounded in generation gaps and Oedipal tensions - in order to declare itself necessary.

Marianne Hirsch (1989), Kathleen Woodward (1995), and Ruth Ray (2003) all offer alternative feminist readings of the Oedipus myth as well as substitute paradigms. For Hirsch, woman-centred myths such as the story of Persephone and Demeter are more useful than Oedipus. She says that classic myths have 'hegemonic power... delimiting force, and ...explanatory potential' (1989:29) but also insists that new theoretical paradigms - that focus on maternal perspectives and don't rely on a divide between mothers and daughters - are vital. Woodward suggests inserting the oftforgotten grandmother into the mother/daughter equation in order to surpass the Oedipal binary. Her revision of the mother/daughter plot encourages us to be flexible about notions of chronology and temporality, seeing ourselves in the bodies of our mothers and grandmothers always, rather than in a dreadful future: '...the figure of the older woman... was in fact present in my past all along, and [she will be] present in my future, time willing.' (1995:92) Feminist gerontologist Ruth Ray argues that while tensions between mothers and daughters can be used to initiate personal growth, we also need other stories through which to relate to each other. She acknowledges that 'in the practice of daily life, it is difficult to resist the pull of the old Freudian psychodrama of mother/daughter conflict. Yet, we must try.' (2003:120)

The issue in relation to cosmetic surgery then, is not only to analyse the destructive Oedipal ways that its discourses pitch women against each other, engendering anxiety and dread - as I have done in the media analysis above - but also to try to identify or suggest alternative paradigms. One such alternative reading of the mother/daughter/cosmetic surgery relation comes from deep inside the practice itself. There is a recently reported 'trend' in mothers and daughters presenting to plastic surgeons together. ${ }^{12}$ (AAFPRS 2003 Survey, 2004:6) Although possibly problematic in all sorts of ways (that begs further research), for my purposes the presentation of mothers and daughters to cosmetic surgeons together points to a phenomenon that can be theorised as running parallel or even in opposition to an Oedipal situation where women are in competition with each other. Cosmetic surgery - and other less violent deployments of the stretched middle age - could encourage new ways for women to enjoy sisterly, friendly relationships that do not rely on competitiveness and opposition. Research into the attitudes, feelings, and relationships of mother/daughter pairs who have undergone cosmetic surgery might surprise us. Unlike the editorial about the Presley women, a London Daily Mail article allows a mother and daughter pair to tell their own story, keeping editorial comment in the affirmative: '[h]eads turn when mother and daughter Carol, 48, and Sarah Hamilton, 24, walk down the High Street, their admirers oblivious to the generation gap between these two petite blondes...' (Levy, 2000:online) Sarah had breast augmentation while her mother Carol had an eyelift and lip implants, and they shared a hospital room. Post-surgery, Carol said, 'For the first time in ages, I played the protective role of a mother... I washed and brushed Sarah's hair, opened doors for her and fed her. It was like having a baby again. The whole experience made us feel incredibly close.' Sarah said, 'I feel proud to walk down the street with such a stunning, young-looking mother.' (Levy, 2000:online) For this pair, cosmetic surgery seems to have re-emphasised traditional mother/daughter roles whilst simultaneously re-designing them as equals. 


\section{Prosthetic Imaginings}

Because of, and as a result of, technologies like cosmetic surgery, we can perceive that a new kind of middle age now stretches through adulthood. This new mode of life is potentially radical in being able to alter traditional understandings of youth, maturity, and old age, and their relationships to each other. If approached imaginatively, the spectrum of the stretched middle age offers the opportunity for all chronological categories of life to be redefined and varied, and the potential for individuals to be more affective in the performance of their age.

It is in this questioning of formerly rigid groupings that cosmetic surgery could be positively instrumental: in presenting the ageing process as optional, designed, varied, and self-managed it could in turn question deep-rooted Oedipal paradigms. However, I have shown that most discourse around cosmetic surgery remains outdated and unimaginative, confusing youth with beauty - and in fact relying on the conflation of youth and beauty - a paradigm which in turn relies on the denigration of the older woman.

If we accept that cosmetic surgery is about changes to the self and self-designing (rather than about trying to recapture lost youth) then it is not too much of an imaginative leap to see that it has possibilities for reconfigurations of bodies and temporalities that move it way beyond a technology of youthful beauty. This reading of cosmetic surgery is controversial, because by moving such a technology away from a paradigm obsessed with simply deleting the signs of age, we may start to imagine it being developed in ways that are outside the boundaries of beauty equalling youth. In separating it from a panic paradigm obsessed with re/presenting youthfulness, we start to imagine situations where it might be used as an optional body modification, at any age, for any thing. For example, cosmetic surgery could be used to score wrinkles on faces and create droopy breasts, as Kathryn Pauly Morgan suggests (1991:22) in a creative moment that is more political than playful. Cosmetic surgery could be purchased to transform a human face into that of a two-dimensional over-exposed cartoon character, as the pop singer Michael Jackson has done. Or perhaps it could be used openly and lavishly to create 'beauty' that is not necessarily conflated with youth: beauty that might include radical reworkings of femininity and masculinity, or to build as yet unthought-of transgender images, or even animalistic images, like Catman and Lizard man, two men who are trying to live up to their names through a variety of surgical modifications (Sprage, online; Anonymous, 'Tiger man wants fur graft,' online). In this schema, even Jocelyn Wildenstein, the high society New Yorker commonly associated with awful cosmetic surgery, may not seem so strange. Cosmetic surgery could even be happily coupled with prosthetics and gene technology, in order to create such wonders as beautiful working wings for humans, a project that North American plastic surgeon Joe Rosen is working on (Slater, 2001).

\section{Conclusion}

While cosmetic surgery grows as part of a suite of body technologies and lifestyle practices that are working to create and maintain the stretched middle age, its radical possibilities are largely ignored by a popular media that prefers to encase it within ancient discourses that privilege conservative panic. Specifically, fear and terror of 
ageing is still embraced, and is deployed as a wedge between mothers and daughters. Only two generations of women exist in this paradigm, and the young is good while the old is evil. Rhetoric around anti-ageing cosmetic surgery continually reemphasises the contained dichotomy of a mere two states of being, especially for women - young and old - by adopting the signs of one in order to stave off the signs of the other.

A stretched, indefinite middle age created via technologies such as cosmetic surgery, combined with societal changes and the lengthening of women's reproductive years, means that a questioning of the notion of the generation gap is unavoidable.

Repositioning our attitudes towards technologies like cosmetic surgery may offer entirely new ways of seeing and experiencing temporality, and could lead to the superfluity of terms such as 'generation gap.' Sadly, while cosmetic surgery grows as part of a suite of body technologies and lifestyle practices that are working to create a swelled period of middle age into which almost every adult will potentially fit, the discourses around it are dealing with its radical possibilities by using outdated and repressive paradigms that undermine the potentially innovative possibilities that it offers.

\section{Acknowledgments}

I am indebted to the two anonymous reviewers, whose comments helped me to flesh out this paper, and to my PhD supervisor, Dr Zoë Sofoulis.

\section{References}

American Academy of Facial Plastic and Reconstructive Surgery 2003 Membership survey: Trends in Facial Plastic Surgery. March 2004: available online at http://www.facial-plastic-surgery.org accessed 1 July 2004

Anonymous, 'Designer Doubles,' NW, Australian Consolidated Press, Australia, September 30 2002:22-23

Anonymous, 'Mother \& Daughter Makeovers,' Beauty on your own terms, online at http://beauty.ivillage.com/makeovers/hm/article accessed 1 July 2004

Anonymous, 'The Look of Love: Couples, Mother/Daughter Teams Head to MDs Office' online at http://www.prnewswire.com/cgibin/stories.pl?ACCT=105\&STORY=/www/story/05-27-2003/0001953579 accessed 1 July 2004

Anonymous, 'Tiger man wants fur graft,' The Guardian, Thursday August 2, 2001, available online at http://www.guardian.co.uk accessed 1 July 2004

'Awful Plastic Surgery: the good, bad, and ugly of celebrity plastic surgery,' online at http://www.awfulplasticsurgery.com/ accessed 1 July 2004 
Biggs, H. 'The Ageing Body,' Real Bodies: A Sociological Introduction, Eds Mary Evans and Ellie Lee, Palgrave Macmillan, London and New York, 2002:167-184

Biggs, S. The Mature Imagination: Dynamics Of Identity In Midlife and Beyond, Open University Press, Philadelphia, 1999

Blum, Virginia, Flesh Wounds: The Culture of Cosmetic Surgery, 2003, University of California Press, Berkeley, Los Angeles, London

Boland, Y. 'Skin Rejuvenators,' Good Medicine Handbook: the complete guide to cosmetic surgery and anti-ageing, ACP Publishing, 1998:28-33

Broadbent, L. 'Age Old Problem,' NW, Australian Consolidated Press, Australia, January 21 2002:22-25

Bytheway, Bill. Ageism, Open University Press, Buckingham 1995

Chaney, D. 'Creating Memories: Some Images of Aging in Mass Tourism,' Images of Aging: Cultural Representations of Later Life, Eds Mike Featherstone and Andrew Wernick, Routledge, London and New York, 1995:209-224

Davis, K. ' 'A Dubious Equality': Men, Woman and Cosmetic Surgery,' Body and Society, Vol 8(1): 2002:49-65

Davis, K. 'Surgical Passing: or why Michael Jackson's nose makes 'us' uneasy,' Feminist Theory, Vol 4 (1), 2003:73-92

Davis, K. 'The Rhetoric of Cosmetic Surgery: Luxury or Welfare?' Enhancing Human Traits: Ethical and Social Implications, Erik Patens (Ed), Georgetown University Press, Washington DC, 1998:124-134

Davis, K. Dubious Equalities and Embodied Differences: Cultural Studies on Cosmetic Surgery, Rowman \& Littlefield Publishers, Inc, Oxford, 2003:41-57

Davis, K. Reshaping the Female Body: the Dilemma of Cosmetic Surgery. New York, Routledge, 1995

De Beauvoir, S. Old Age, Penguin, England, 1970

Featherstone, M. and Wernick, A. 'Introduction,' Images of Aging: Cultural Representations of Later Life Eds Mike Featherstone and Andrew Wernick, Routledge, London and New York, 1995:1-15

Fischer, D. Growing Old in America, Oxford University Press, Oxford, 1978

Fraser, S. Cosmetic Surgery, Gender and Culture, Palgrave Macmillan, London and New York, 2003

Friedan, B. The Fountain of Age, Vintage, London, 1994 
Gatens, M. Imaginary Bodies: Ethics, Power and Corporeality, Routledge, London and New York, 1996

Gilleard, C. and Higgs, P. Cultures of Ageing: Self, Citizen and the Body, Prentice Hall, Harlow, 2000

Gillis, J. R. 'Vanishing youth: The uncertain place of the young in a global age,' YOUNG: Nordic Journal of Youth Research, Volume 1 Number 11993 online at http://www.alli.fi/nyri/young/1993-1/y931gill.htm accessed 1 July 2004

Gillis, J. R. Youth and history: Tradition and change in European age relations, 1770 to the present, Academic Press, New York, 1975

Gilman, S. L. Making the Body Beautiful: A Cultural History of Aesthetic Surgery, Princeton, New Jersey, Princeton University Press, 1999

Gordon, M.L. 'Will You Age Like Your Mother?' Marie Claire, July 2004

Gullette, M. Aged by Culture, The University of Chicago Press, London, 2004

Gullette, M. Declining to Decline, The University Press of Virginia, Charlottesville and London, 1997

Haiken, E. Venus Envy: a History of Cosmetic Surgery. Baltimore, Maryland: The Johns Hopkins

University Press, 1997

Haobsh, N. 'Mother-Daughter Beauty' Ladies Home Journal, 2004, online at www.lhj.com accessed 1 July 2004

Hareven, T.K. 'Changing Images of Aging and the Social Construction of the Life Course,' Images of Aging: Cultural Representations of Later Life Eds Mike

Featherstone and Andrew Wernick, Routledge, London and New York, 1995:119-134

Hine, T. The Rise and Fall of the American Teenager, Harper Collins, New York, 1999

Hirsch, M. The Mother/Daughter Plot: Narrative, Psychoanalysis, Feminism, Indiana University Press, Bloomington and Indianapolis, 1989

Hockey, J. and James, A. 'Back to Our Futures: Imaging Second Childhood,' Images of Aging: Cultural Representations of Later Life Eds Mike Featherstone and Andrew Wernick, Routledge, London and New York, 1995:135-148

Hodgkinson, D. 'Are These Stars Cheating Their Genes?' Gloss: The Essential AntiAgeing Magazine, Atlantic and Pacific Publishing, Sydney, October/November 1998: 24-26 
Kaplan, E.A. 'Trauma and Aging: Marlene Dietrich, Melanie Klein, and Marguerite Duras,' Figuring Age: Women, Bodies, Generations Ed Kathleen Woodward, Indiana University Press, Bloomington and Indianapolis, 1999:171-194

Karash, J, and Smith Knight, J. 'Family Finds Price of Beauty Worth Results' Dayton Daily News, June 6, 2000: available online at http://www.personalsurgeon.com/library/familyfindsprice.asp accessed 1 July 2004

Katz, S. 'Imagining the Life-span: From Premodern Miracles to Postmodern Fantasies,' Images of Aging: Cultural Representations of Later Life Eds Mike Featherstone and Andrew Wernick, Routledge, London and New York, 1995:61-75

Levy, M. 'Cosmetic Surgery Brought Us Closer,' Daily Mail, London, April 25, 2000: available online at www.personalsurgeon.com/library/broughtuscloser.asp accessed 1 July 2004

Macdonald, B. Look me in the eye: old women, aging, and ageism, Spinsters Ink, Denver, Colorado, 2001

Morgan, K. 'Women and the Knife: Cosmetic Surgery and the Colonization of Women's Bodies,' Hypatia 6 (3), 1991:25-53

Ray, R. E. 'The uninvited guest: mother/daughter conflict in feminist gerontology,' Journal of Aging Studies, Vol 17, Issue 1, February 2003:113-128

Ring, A. 'Anti-ageing in the era of the older person,' Everybody (VicHealth), Vol 5, March, 1999:10-12

Ring, A. 'Cosmetic surgery magazines: mass mediating the new face of medical practice,' Australian Studies in Journalism, Vol 8, 1999:118-138

Ring, A. 'The countdown to new heights of sexist ageism in the media of the new world order,' M. Alexander et al (Eds) Refashioning Sociology: Responses to a New World Order, The Australian Sociological Association 1998 Conference Proceedings, QUT Publications and Printing, Brisbane, 1998:87-96

Ring, A. 'The Marketing of cosmetic surgery: doctors and the beauty trade,' The Australian Health Consumer, No 2, 1999:20-22

Ring, A. 'Using 'anti-ageing' to market cosmetic surgery: just good business, or another wrinkle on the face of medical practice?' Medical Journal of Australia 176 (12), 2002:597-599

Slater, L. 'Dr. Daedalus: A Radical Plastic Surgeon Wants to Give You Wings.' Harper's Magazine, July 2001:57-67.

Sophocles, Antigone, Oedipus the King, Electra. Trans. H.D.F. Kitto, Ed. Edith Hall, Oxford University Press, Oxford, 1994 
Sprague, E. Homepage of 'The Lizardman,' online at http://bmeworld.com/amago/ accessed 1 July 2004

Stewart, S. On Longing, Duke University Press, Durham and London, 1993

Tseëlon, E. The Masque Of Femininity: Presentation Of Woman In Everyday Life, Sage, London, 1995

Walz T. 'Crones, Dirty Old Men, Sexy Seniors: Representations of the Sexuality of Older Persons,' Journal of Aging and Identity, Vol 7 No 2, June 2002:99-112

Woodward, K. 'Tribute to the Older Woman: Psychoanalysis, Feminism and Ageism,' Images of Aging: Cultural Representations of Later Life Eds Mike Featherstone and Andrew Wernick, Routledge, London and New York, 1995:79-96

[Extra bits for chapter version:

Wepsic, R. M. (1996). "Cosmetic Surgery and Images of Aging Women: Constructing Differences by Race and Class." Society for the Study of Social Problems.

Recent popular articles on cosmetic surgery \& the strong market for facelifts \& other "antiaging" surgeries suggest that mid-life \& older women are seeking cosmetic surgery to remain competitive in the job market. The baby boomer generation, in particular, is cited as a large group of potential cosmetic surgery customers. Much of cosmetic surgery marketing is directed toward mid-life women, $\&$ many cosmetic surgeries have been developed for the purpose of trying to retain a young face. Focus here is on how this marketing is implicitly raced \& classed. Drawing on Ruth Frankenberg's (1993) study of the social construction of whiteness, discussed is how surgery practices materially construct cultural ideals of whiteness, affluence, womanliness, $\&$ the pursuit of youth. Because cosmetic surgery is a particularly localized practice, with a population composed primarily of white, uppermiddle- \& upper-class women, it is a powerful site for examining the reproduction \& creation of these differences. By focusing on a social phenomenon that is notably raced, classed, gendered, \& aged, a better understanding of how these differences are created $\&$ sustained (as well as physically inscribed) can be achieved.

Extra quotes from Blum:

Blum's mother took her to a cosmetic surgeon at 18 to have her 'too wide' 'too Jewish' nose 'refined.' She compares her experience to those of Asian girls whose mothers take them to have double-lid surgery (work on the epicanthal fold to make the eyes appear bigger and more Western): 'Mothers take their sixteen-year-old daughters for double-lid surgery; they present it to them with love, kisses, and their blessings as a high school graduation present.']

\footnotetext{
Notes

${ }^{1}$ Expressed very simply, 'Makeover Culture' is a term I have constructed to describe a set of cultural logics where becoming is more desirable than being. I take the term makeover from popular culture, where it is applied to a range of lifestyle practices including cosmetic surgery, home renovation, gardening, and even business invigoration. Makeover connotes the spatial and temporal period of change: it concentrates more on the process of development than on the idea of completion. For individuals, the paradigm of makeover rewards the display of continual development, improvement and
} 
growth made via intellectual, emotional, or aesthetic means. I argue that in the Makeover Culture, success is judged on the display of the never-ending renovation of the self.

${ }^{2}$ Anne Ring convincingly argues that these magazines have been created in line with the progressive deregulation of advertising by medical practitioners in Australia. She demonstrates in a series of articles that there are ethically questionable links between articles and advertisements in the magazines. (Ring, 1998, 1999a, 1999b, 1999c, 2002)

${ }^{3}$ Thomas Walz notes that representations of sexuality of ageing people in popular culture have changed somewhat in recent years. He documents a movement in popular media that shows older people to be healthy, engaged, and attractive. Importantly though, positive light is only thrown on those individuals who '... are aging well (i.e., who look and act young)' (Walz, 2002:99). For my purposes then, it is those individuals who are displaying engagement with the makeover culture and who have invested in stretching their middle age who are benefiting from this improvement in representation.

4 'Youth' is a relatively new category, developed as part of western capitalist industrialisation in the period post WWI (Hine, 1999:237-8; Hareven, 1995:123)

${ }^{5}$ All efforts have been made to secure copyright for this image. If anyone has any information about the owner/s of the copyright for it they should contact the author.

${ }^{6}$ My interviews, with 17 cosmetic surgery recipients, have been in-depth and qualitative.

${ }^{7} N W$ is a weekly magazine located at the 'trashy/gossipy' end of the market. It is sold in newsagents but is also marketed at supermarket checkouts and costs $\$ 4.20$.

${ }^{8}$ The issue of Marie Claire current at the time of writing (July 2004) has an article called 'Will You Age Like Your Mother?' available online at http://magazines.ivillage.com/marieclaire/beauty/skin/articles/0,434727 641725,00.html

${ }^{9}$ All efforts have been made to secure copyright for this image. If anyone has any information about the owner/s of the copyright for it they should contact the author.

${ }^{10}$ Some of the women I interviewed expressed profound interest in not looking like their ageing mothers. One told me:

I'm about as old now as my mother [was] when I first begin to [see her] as a woman, as opposed to my mother... I've sort of realised that I'm quite like her now... I got her body... I always noticed this thing about my mother's body, which was... that she had like a fat build up in her thighs... I can't remember when I first noticed my own thighs, but certainly now, I definitely know that... the worst part of my body is my thighs, which is why I'm thinking about going and having liposuction.

And in an inversion of sorts, some women express pleasure in the results of their cosmetic surgery in terms of similarities to their daughters: one 38 year old said after liposuction: 'My butt looks like my 14-year-old daughter's... I never would have dreamed that was possible' (quoted in Karash and Smith Knight: 2000, online). And one of my interviewees, a woman who had breastfed four children, told me after having breast implants:

Before, I had nothing left at all. All I had was a nipple and it was hanging over itself like a crease... [Now] I'm rapt, totally rapt, going shopping and trying on clothes is just so great, I can do it with [my 16 year old daughter] and I don't feel bad because you know, she has the most lovely little round breasts.

${ }^{11}$ All efforts have been made to secure copyright for this image. If anyone has any information about the owner/s of the copyright for it they should contact the author.

$1244 \%$ of member-surgeons of the American Academy of Facial Plastic and Reconstructive Surgery reported that mother-daughter pairs had consulted them in 2003. While there are no previous statistics for comparison, the fact that the question was included in the 2003 survey suggests that the phenomena had increased. 